\title{
Squamous Cell Carcinoma of the External Auditory Canal
}

\author{
David Lobo, M.D., 1 José L. Llorente, M.D., Ph.D., 1 \\ and Carlos Suárez, M.D., Ph.D. ${ }^{1}$
}

Objectives: This study aims to analyze the treatments, prognostic variables, and outcomes of patients with squamous cell carcinomas (SCC) of the external auditory canal (EAC) and middle ear treated in our department over a 15-year period. Design: A retrospective analysis of 19 patients treated in our department between 1990 and 2006. The patients were staged according to the Pittsburgh classification. Patients were treated with either a lateral (LTBR) or an extended temporal bone resection (total or subtotal). Parotidectomy was performed in patients with suspected clinical or radiological invasion and postoperative radiotherapy was the adjuvant treatment in most patients in advanced stages. Results: The overall 5-year survival was $37 \%$. There were no patients in stage I. The survival rates were $100 \%, 25 \%$, and $16 \%$ for stages II, III, and IV, respectively. Facial nerve paralysis $(p=0.007)$ and lymph node involvement $(p=0.006)$ were associated with decreased survival rates. Conclusion: SCC of the temporal bone are rare but have a poor prognosis. Lymph node involvement and facial nerve palsy are associated with a poorer outcome. These tumors must initially be treated radically, for which an early diagnosis is important.

KEYWORDS: Carcinoma of the external auditory canal, squamous cell carcinoma, ear neoplasms, temporal bone surgery, temporal bone tumors

Carcinoma of the temporal bone represents one out of 5000 to 20,000 otologic cases, ${ }^{1,2}$ with an incidence between 1 and 6 cases per million population per year. ${ }^{3,4}$ Squamous carcinoma is the most frequent neoplasm in the external auditory canal (EAC), about four times more common than basal carcinomas. This ratio is reversed in the pinna. Unlike squamous carcinomas of the auricle, which

${ }^{1}$ Department of Otorhinolaryngology, Hospital Universitario Central de Asturias, Oviedo, Spain.

Address for correspondence and reprint requests: José L. Llorente, M.D., Ph.D., C/ J.M. Caso 14, 33006 Oviedo, Asturias, Spain (e-mail: 1lorentependas@telefonica.net).

Skull Base 2008;18:167-172. Copyright (C) 2008 by Thieme are consistently associated with actinic damage, no such relationships exist for lesions in the auditory canal. ${ }^{5}$ These tumors have been associated with chronic suppurative otitis media and exposure to chemicals, though the most important factor may be previous radiotherapy. ${ }^{6}$

Most squamous cell carcinomas (SCC) of the temporal bone occur in the fifth and sixth decades of

Medical Publishers, Inc., 333 Seventh Avenue, New York, NY 10001, USA. Tel: +1(212) 584-4662.

Received: June 13, 2007. Accepted: June 23, 2007. Published online: November 28, 2007.

DOI 10.1055/s-2007-994290. ISSN 1531-5010. 
life. Otorrhea is the primary symptom, and otalgia, hearing loss, and bleeding may be frequent as well. Diagnosis is usually delayed because symptoms are quite similar to other benign otologic conditions such as chronic suppurative otitis media.

These tumors have an aggressive nature and spread along preformed vascular and neural pathways, invading adjacent structures. ${ }^{1}$ Treatment usually combines surgery with free margins and radiotherapy. Surgery alone may be used for very early stages (T1), whereas radiotherapy alone is rarely used.

The extent of disease, positive margins, dural involvement, facial nerve paralysis, cranial nerve involvement, or moderate to severe pain on presentation have been associated with poorer outcomes. $^{7}$

Early surgical attempts to remove these tumors usually involved high morbidity and mortality. These mortality rates have substantially decreased from Lewis's ${ }^{8}$ series to the more recent series of Moffat et $\mathrm{al}^{9}$ and Yin and associates ${ }^{10}$ as a result of advances in surgery and radiotherapy in the last three decades. The overall 5-year survival rates rank between $40 \%$ and $70 \%$, but only reach $20 \%$ when advanced stages are considered. The main cause of death is local recurrence rather than regional or metastatic disease. ${ }^{11,12}$

\section{MATERIAL AND METHODS}

This study is a retrospective analysis of 19 patients with SCC of the temporal bone (11 men and 8 women between 38 and 84 years old [mean age, $65 \mathrm{y}$; range, 38 to $84 \mathrm{y}]$ ), who were treated at our institution between 1990 and 2006. In an earlier study, 13 patients were analyzed using the classification system proposed by Shih and Crabtree. ${ }^{13}$ These patients have not been included in the present study. ${ }^{14}$ We have specifically excluded patients with tumors that invaded temporal bone from adjacent structures, metastatic tumors, and tumors of the pinna. Patients were classified according to the classification system proposed by Arriaga et al in $1990 .{ }^{15}$

Seven patients $(37 \%)$ had a history of previous radiotherapy on this area between 2 and 24 years before presentation, (mean, 11 y). Five patients (26\%) had chronic suppurative otitis media, 2 patients (11\%) had other epidermoid or basocellular skin cancer, and 7 (37\%) were smokers. Some of them presented several of these predisposing factors.

Symptoms had been present between 2 weeks and more than 1 year, although most of the patients had symptoms for 1 to 6 months before consultation. Most frequent symptoms and signs were otorrhea (13 patients), otalgia (9), hearing loss (6), bleeding (5), and facial palsy (4). Less frequent was the presence of an aural or preauricular mass.

All patients received preoperative and postoperative computed tomography (CT) scans and/ or magnetic resonance. Following the classification of Medina and associates, patients with T2N0 tumors were treated with an LTBR. Patients with stage III or IV were treated with either an LTBR or an extended temporal bone resection (total or subtotal) ${ }^{16}$.

We performed a parotidectomy in tumors involving the anterior wall of the EAC. We performed neck dissection only in the case of clinically positive necks. We obliterated the EAC and most of the time reconstructed the defect with a temporalis muscle flap. Two patients were lost to follow up.

\section{RESULTS}

The distribution of the patients by stages is shown in Table 1. There were no patients with T1N0 disease (stage I). Three patients (16\%) presented with T2N0 disease (stage II) and 3 patients (16\%) had T3N0 disease (stage III). Finally, there were 13 patients (68\%) in stage IV. Ten patients (53\%) presented with T4N0 disease, 1 patient (5\%) presented with T2N1 disease, 1 patient (5\%) presented 
Table 1 Distribution of Patients by Stages According to the Classification System Proposed by Arriaga and colleagues $^{15}$

\begin{tabular}{lll}
\hline & $\begin{array}{l}\text { N0 (Number } \\
\text { of Patients) }\end{array}$ & $\begin{array}{l}\text { N1-2-3 (Number } \\
\text { of Patients) }\end{array}$ \\
\hline T1 & I (0) & III (0) \\
T2 & II (3) & IV (2) \\
T3 & III (3) & IV (0) \\
T4 & IV (10) & IV (1) \\
\hline
\end{tabular}

with T2N2 disease and another patient (5\%) presented with T4N1 disease.

If we consider the surgical technique, six patients (32\%) underwent an LTBR type II, five patients (26\%) underwent an LTBR type III, and six patients $(32 \%)$ a total or subtotal temporal resection. Two patients were treated palliatively because they had temporal lobe involvement and were medically unfit for surgery; these patients were excluded from the analysis (Table 2).

A superficial parotidectomy was performed in three patients (all patients had T4 disease, and the facial nerve had to be sacrificed), and a total parotidectomy was performed in six patients (one patient had T3 disease and five patients had T4 disease, the facial nerve being preserved in two patients with T4 disease).

The temporalis flap was the most commonly used muscle flap for reconstruction in 14 patients, although an assortment of techniques such as skin grafts (5 patients), parascapular free flap (1 patient), and sternocleidomastoid flap (1 patient) were also used.

Twelve patients received postoperative radiotherapy, and one patient received radiotherapy and chemotherapy after surgical resection.

As complications, five patients developed a cerebrospinal fluid leak. Two cases resolved after bedrest in a semisitting position, two cases required a lumbar puncture, and in one case we used an abdominal fat graft to close the fistula 1 month after surgery. Two patients presented wound dehiscence and infection, one patient presented a temporal seroma, and finally one patient suffered acute myocardial infarction, followed by acute pulmonary
Table 2 Clinical Distribution of Patients with (Squamous Cell Carcinoma) of the External Ear and Survival Outcome

\begin{tabular}{|c|c|c|c|c|}
\hline $\begin{array}{l}\text { Patient } \\
\text { Age }\end{array}$ & Stage & Treatment & $\begin{array}{l}\text { Follow-Up } \\
\text { (mo) }\end{array}$ & Outcome \\
\hline 53 & T4NO & LTBR ॥ & 0.36 & LNED \\
\hline 69 & T2NO & LTBR II & 0.4 & DOC \\
\hline 78 & T4NO & No surgery & 1.7 & DOD \\
\hline 70 & T2N1 & LTBR II + RT & 2.5 & DOD \\
\hline 84 & T4NO & No surgery & 4.6 & DOD \\
\hline 38 & T4N1 & $\mathrm{TTBR}+\mathrm{RT}+\mathrm{QT}$ & 6.5 & DOD \\
\hline 62 & T4NO & STTBR + RT & 6.8 & NED \\
\hline 78 & T4NO & LTBR III + RT & 7 & NED \\
\hline 80 & T4NO & LTBR III + RT & 10.4 & DOD \\
\hline 47 & T4NO & LTBR III + RT & 12.3 & DOD \\
\hline 54 & T3NO & $\mathrm{TTBR}+\mathrm{RT}$ & 16.2 & DOD \\
\hline 80 & T3NO & LTBR III & 24.2 & DOD \\
\hline 54 & T4NO & $\mathrm{TTBR}+\mathrm{RT}$ & 25.9 & NED \\
\hline 66 & T2N2 & LTBR II + RT & 29.8 & LNED \\
\hline 79 & T4NO & LTBR III + RT & 36.5 & DOD \\
\hline 84 & T2No & LTBR ॥ & 47.8 & DOC \\
\hline 51 & T2No & LTBR II + RT & 69.8 & NED \\
\hline 75 & T4NO & $\mathrm{TTBR}+\mathrm{RT}$ & 105.5 & NED \\
\hline 45 & T3NO & $\mathrm{TTBR}+\mathrm{RT}$ & 170.3 & NED \\
\hline
\end{tabular}

LTBR, lateral temporal bone resection; LNED, patient lost without evidence of disease; DOC, died of other causes; DOD, died of disease; RT, postoperative radiotherapy; TTBR, total temporal bone resection; QT, chemotherapy; STTBR, subtotal temporal bone resection; NED, no evidence of disease.

edema and brainstem infarction; this patient died in the early postoperative period.

The 5-year disease free survival in our series has been 37\% (Fig. 1). The disease free survival for stage II was $100 \%$, for stage III $25 \%$, and for stage IV $16 \%$.

Nine patients died during the study, two who received palliation only because their tumors were inoperable, four due to local or regional recurrence, and three of distant metastasis and locoregional recurrence. Of these patients, $60 \%$ died during the first year after the surgery and another $25 \%$ died during the second year. Two patients died of other causes and two patients were lost without evidence of disease. The mean follow-up time of the censored patients was 20 months.

Six patients (31.2\%) presented positive nodes, and all except for a lost patient have died of the disease 2 years after surgery. The 5 -year survival 


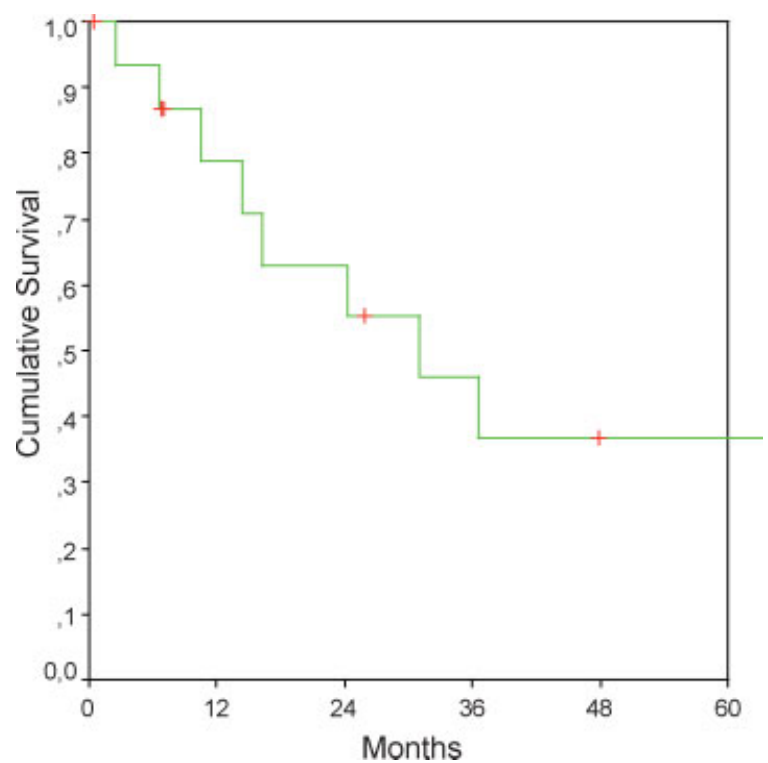

Figure 1 Chart shows 5-year overall survival of the series.

rate in N0 patients was 61\%, whereas in $\mathrm{N}+$ patients it was $0 \%$ (statistically significant difference; $p=0.006$ ) (Fig. 2).

Four patients had facial palsy at presentation. Survival rate in this group of patients $(0 \%)$ was significantly lower than in the rest of the patients (47\%) $(p=0.007)$ (Fig. 3). Finally, only one of the

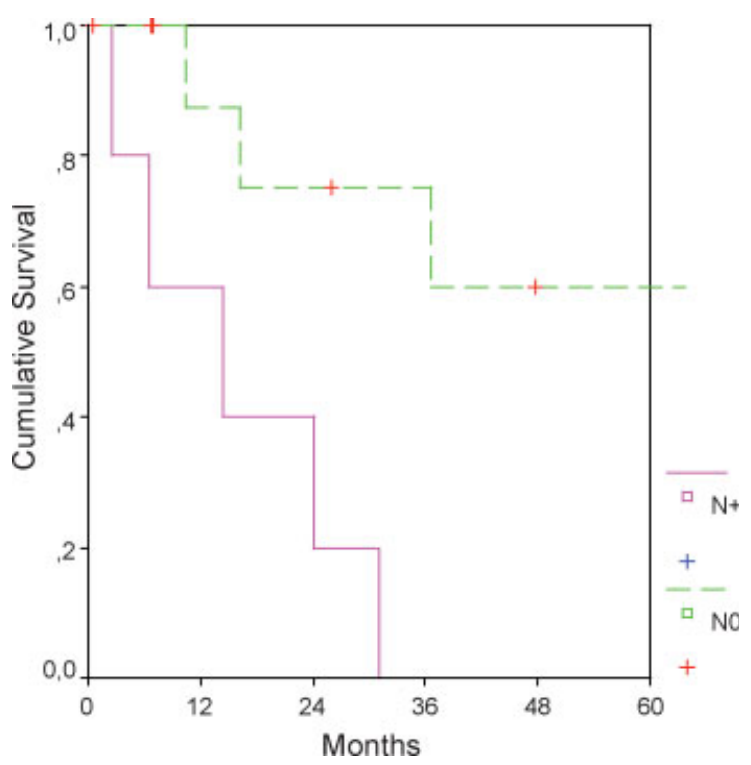

Figure 2 Chart shows disease-free survival of NO and $\mathrm{N}+$ patients $(p=0.006)$.

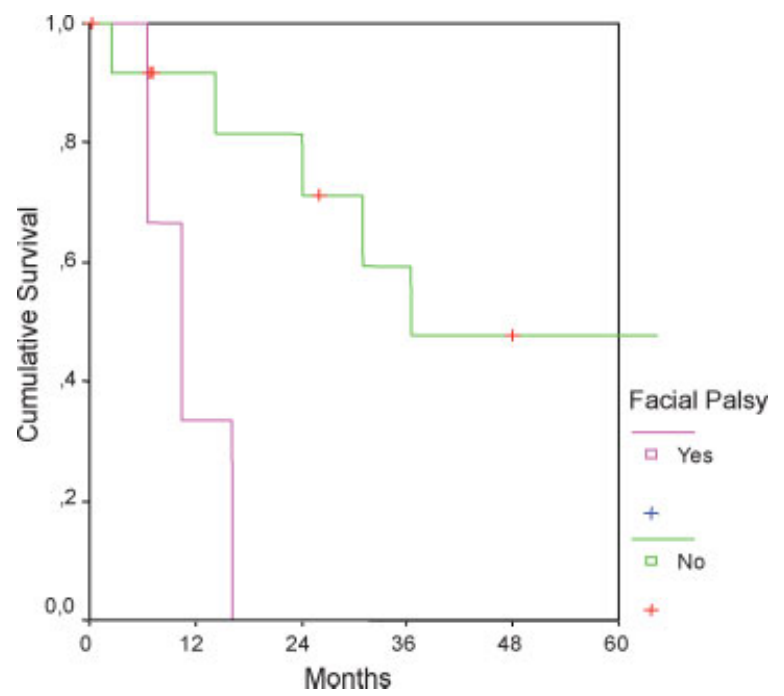

Figure 3 Chart shows facial palsy at presentation $(p=0.007)$.

three patients with intracranial extension remains alive free of disease 7 months after surgery.

Ten patients had well-differentiated tumors, six patients had moderately differentiated tumors, and three patients had poorly differentiated tumors. Well-differentiated tumors did not show significant longer survival (51\%) than moderately or poorly differentiated tumors (0\%) $(p=0.07)$ (Fig. 4).



Figure 4 Chart shows disease-free survival of poor versus moderate or well-differentiated tumors ( $p=0.07)$. 


\section{DISCUSSION}

If we consider the demographic variables of our series we find a slight predominance of men, which agrees with other published series, although in larger revisions a clear predominance of sex has not been observed. ${ }^{1,4,10,17}$ Among the predisposing factors the most important in our series is the antecedents of previous head and neck radiotherapy for nasopharyngeal cancer or skin neoplasms in seven patients.

SCC generally have a more aggressive behavior and a worse prognosis than other tumors of the auditory canal and middle ear. The overall 5year survival for the entire series has been $37 \%$, and for stage IV tumors $16 \%$. The overall cure rate varied in different reports from 43.2 to $66.8 \%$, and survival for stage IV disease from 0 to $34.3 \%$., $3,9-11$

Local recurrence and distant metastasis were recognized in $37 \%$ and $16 \%$ of patients, respectively, lower rates than those found in other series, although higher rates of recurrence have also been reported. ${ }^{3,11}$

Of the patients who have died $44.4 \%$ had local recurrence, and $33.3 \%$ died of distant metastasis besides locoregional recurrence. Two patients (22.2\%) died of inoperable tumors.

The therapeutic protocols have been evolving over the last several years, although surgery is still the key when facing this type of tumor. The surgical technique is well standardized by Medina and others. ${ }^{16}$ The aim is a complete removal of the tumor with free margins (that for large tumors may be accomplished in a piecemeal manner), followed by postoperative radiotherapy. We consider that SCC that invades the carotid or with evident middle or posterior fossa invasion is unresectable.

Lymph node metastasis at surgery was found in $16 \%$ of patients in our series, similar to other reports. ${ }^{9-11}$ Due to the possibility of node metastasis in a 10 to $20 \%$ of the patients, it seems justified to perform a supraomohyoid or functional neck dissection. A superficial parotidectomy also seems reasonable given the low added morbidity, although we have only performed a parotidectomy in patients with suspected clinical or radiological extension of the tumor to the parotid gland, or in the case of parotid node metastasis. Choi and colleagues ${ }^{18}$ found parotid node metastasis in only 2 cases out of 12 with EAC SCC, both in advanced stages.

The most recent papers recommend the use of postoperative radiotherapy in all cases, with better results when the resection margins have been negative. ${ }^{19}$ In our series we have not found significant differences, although a tendency toward a better survival rate was found in the group treated with surgery and radiotherapy, compared with the group treated only with surgery in stages III and IV. Some authors propose chemotherapy for stages III and IV. ${ }^{10}$ Complementary therapy with topical 5-fluorouracil cream application has also been studied. ${ }^{20}$

Most important unfavorable prognostic factors were the presence of neck node metastasis and the presence of facial palsy at the diagnosis, both of them statistically significant. These results corroborate those reported in other papers. ${ }^{2,3,7,9-11}$ Facial palsy at presentation was an ominous sign in our study as all patients died within 16 months after surgery. Facial nerve involvement could modify the tumor stage as Hirsch ${ }^{21}$ first recommended. Dural involvement and degree of differentiation did not predict a worse outcome in our study, but the number of patients with dural involvement or undifferentiated tumors was too small to obtain reliable results.

We could not find a statistically significant difference when we compared tumors of different stages. There were only three patients in stage II. Two of them died of unrelated causes (brainstem infarction 4 months after surgery and gastric carcinoma 48 months after surgery), and the third is alive free of disease 70 months after surgery. The small number of patients in stage II precluded meaningful statistical analysis.

When the initial removal of the tumor is inadequate, survival rates fall dramatically. Moffat et $\mathrm{al}^{9}$ found better survival in patients treated de novo than in those who were referred from other institutions, possibly due to the fact that the latter 
presented with more aggressive tumors or because radical surgery was not performed initially. In our series this same tendency was observed in patients with stage IV: those who underwent a total temporal resection showed the longe st survival (105 and $170 \mathrm{mo})$.

Malignant tumors of the EAC and middle ear are rare, but are associated with high morbidity and mortality rates. SCC is the most frequent histologic type, arising mainly in the auditory canal rather than in the middle ear.

These tumors are diagnosed in a late stage most of the time because initial symptoms are similar to those of other (benign) diseases. In addition, there is a lack of clear anatomical barriers that prevent tumor progression. Prognosis depends on the tumor stage, the presence of positive nodes, facial paralysis, or intracranial extension with invasion of the dura.

Treatment of EAC carcinomas is generally based on the combination of surgery and radiotherapy. Patients with EAC must initially be treated radically, and for them, early diagnosis and referral to an institution with experience in this kind of surgery is important. In addition to postoperative treatment with radiotherapy, it seems advisable to evaluate the response to different lines of chemotherapy used in SCC of the head and neck. This is especially important for tumors in advanced stages that present with features associated with poor prognosis, due to the short life expectancy under these circumstances given current treatments.

\section{REFERENCES}

1. Barrs DM. Temporal bone carcinoma. Otolaryngol Clin North Am 2001;34:1197-1218

2. Manolidis S, Pappas D, Von Doersten P. Temporal bone and lateral skull base malignancy: experience and results with 81 patients. Am J Otol 1998;19(suppl):S1-S15

3. Isipradit P, Wadwongtham W, Aeumjaturapat S, Aramwatanapong P. Carcinoma of the external auditory canal. J Med Assoc Thai 2005;88:114-117

4. Kuhel WI, Hume CR, Selesnick SH. Cancer of the external auditory canal and temporal bone. Otolaryngol Clin North Am 1996;29:827-852
5. Devaney KO, Boschman CR, Willard SC, Ferlito A, Rinaldo A. Tumours of the external ear and temporal bone. Lancet Oncol 2005;6:411-420

6. Lim LH, Goh YH, Chan YM, et al. Malignancy of the temporal bone and external auditory canal. Otolaryngol Head Neck Surg 2000;122:882-886

7. Testa JRG, Fukuda Y, Kowalski LP. Prognostic factors in carcinoma of the external auditory canal. Arch Otolaryngol Head Neck Surg 1997;123:720-724

8. Lewis JS. Temporal bone resection: review of 100 cases. Arch Otolaryngol 1975;101:23-25

9. Moffat DA, Wagstaff SA, Hardy DG. The outcome of radical surgery and postoperative radiotherapy for squamous carcinoma of the temporal bone. Laryngoscope 2005;115:341-347

10. Yin M, Ishikawa K, Honda K, et al. Analysis of 95 cases of squamous cell carcinoma of the external and middle ear. Auris Nasus Larynx 2006;33:251-257

11. Yoon M, Chogule P, Dufresne R, Wanebo H. Localized carcinoma of the external ear is an unrecognized aggressive disease with a high propensity for local regional recurrence. Am J Surg 1992;164:574-577

12. Sasaki CT. Distant metastasis from ear and temporal bone cancer. ORL J Otorhinolaryngol Relat Spec 2001;63:250251

13. Shih L, Crabtree JA. Carcinoma of the external auditory canal: an update. Laryngoscope 1990;100:12151218

14. Baldo Sierra C, Suarez Nieto C, Llorente Pendas JL, Bernardo Corte MJ. Primary tumors of the external auditory canal [in Spanish]. Acta Otorrinolaringol Esp 1992;43:439-442

15. Arriaga M, Cartin H, Hirsch BE, Takahashi H, Kammerer DB. Staging proposal for external auditory meatus carcinoma based on preoperative clinical examination and CT findings. Ann Otol Rhinol Laryngol 1990;99: 714-721

16. Medina JE, Park AO, Neely JG, Hill Britton B. Lateral temporal bone resections. Am J Surg 1990;160:427433

17. Rodríguez Paramás A, Gil Carrasco R, Arenas Britez O, Yurrita Scola B. Malignant tumours of the external auditory canal and of the middle ear [in Spanish]. Acta Otorrinolaringol Esp 2004;55:470-474

18. Choi JY, Choi EC, Lee HK, Yoo JB, Kim SG, Lee WS. Mode of parotid involvement in external auditory canal carcinoma. J Laryngol Otol 2003;117:951-954

19. Hashi N, Shirato H, Omatsu T. The role of radiotherapy in treating squamous cell carcinoma of the external auditory canal, especially in the early stages of disease. Radiother Oncol 2000;56:221-225

20. Knegt PP, Ah-See KW, Meeuwis CA, van der Velden LA, Kerrebijn JD, De Boer MF. Squamous carcinoma of the external auditory canal: a different approach. Clin Otolaryngol Allied Sci 2002;27:183-187

21. Hirsch BE. Staging system revision. Arch Otolaryngol Head Neck Surg 2002;128:93-94 